\title{
Silicon carbide nanocomposites reinforced with disordered graphitic carbon formed in situ through oxidation of $\mathrm{Ti}_{3} \mathrm{C}_{2}$ MXene during sintering
}

\author{
M. Petrus ${ }^{1}$ (D) J. Woźniak ${ }^{1} \cdot$ T. Cygan ${ }^{1} \cdot$ A. Lachowski ${ }^{2} \cdot$ A. Rozmysłowska-Wojciechowska $^{1} \cdot$ T. Wojciechowski $^{3}$. \\ W. Ziemkowska ${ }^{3} \cdot$ L. Chlubny ${ }^{4} \cdot$ A. Jastrzębska ${ }^{1} \cdot$ B. Adamczyk-Cieślak ${ }^{1} \cdot$ A. Olszyna ${ }^{1}$
}

Received: 26 November 2020 / Revised: 6 April 2021 / Accepted: 25 April 2021 / Published online: 21 May 2021

(c) The Author(s) 2021

\begin{abstract}
This article describes the manufacturing of silicon carbide composites with the addition of quasi-two-dimensional titanium carbide $\mathrm{Ti}_{3} \mathrm{C}_{2}$, known as MXene. The composites were obtained by the powder metallurgy technique, consolidated with the use of the Spark Plasma Sintering method at $1900{ }^{\circ} \mathrm{C}$ and dwelled for $30 \mathrm{~min}$. The influence of the $\mathrm{Ti}_{3} \mathrm{C}_{2} \mathrm{MXene}$ addition on the microstructure and mechanical properties of the composites was investigated. The structure of the MXene phase after the sintering process was also analyzed. The results showed a significant increase (almost 50\%) of fracture toughness for composites with the addition of $0.2 \mathrm{wt} \% \mathrm{Ti}_{3} \mathrm{C}_{2}$ MXene. In turn, the highest hardness, $23.2 \mathrm{GPa}$, was noted for the composite with the addition of the $1.5 \mathrm{wt} \% \mathrm{Ti} 3 \mathrm{C} 2 \mathrm{MXene}$ phase. This was an increase of over $10 \%$ in comparison to the reference sample. The analysis of chemical composition and observations using a transmission electron microscope showed that the Ti3C2 MXene phase oxidizes during sintering, resulting in the formation of crystalline, highly defected, disordered graphite structures. The presence of these structures in the microstructure, similarly to graphene, significantly affects the hardness and fracture toughness of silicon carbide.
\end{abstract}

Keywords Ceramic matrix composites $(\mathrm{CMCs}) \cdot$ Mechanical properties $\cdot$ Sintering $\cdot$ MXene

\section{Introduction}

Silicon carbide ( $\mathrm{SiC}$ ), aside from a number of advantages such as high hardness, high wear resistance and the stability of these properties in a broad temperature range, also shows low fracture toughness, which drastically limits its potential applications [1-3]. To eliminate this disadvantage, in addition to the development of novel sintering technique [4-6],

M. Petrus

mateusz.petrus.dokt@pw.edu.pl

1 Faculty of Materials Science and Engineering, Warsaw University of Technology, Woloska 141, 02-507 Warsaw, Poland

2 Institute of High Pressure Physics, Polish Academy of Sciences, Sokolowska 29/37, 01-142 Warsaw, Poland

3 Faculty of Chemistry, Warsaw University of Technology, Noakowskiego 3, 00-664, Warsaw, Poland

4 Faculty of Materials Science and Ceramics, AGH University of Science and Technology, A. Mickiewicza 30, 30-059 Cracow, Poland the production of composites has become necessary. There are a few materials that can be used as reinforcements in silicon carbide matrix composites and which improve fracture toughness without reducing other properties, such as hardness or thermal stability, e.g., SiC-carbon fiber composites [7] or $\mathrm{SiC} / \mathrm{SiC}$ composites [8]. The progress in methods of manufacturing two-dimensional (2D) materials, initiated by Geim and Novoselov obtaining graphene, created an opportunity for the development of a new family of composites reinforced with 2D crystals [9]. The use of graphene and other graphene family materials (GFM), such as graphene oxide or metal-coated graphene, in ceramic matrix composites caused significant changes in the microstructure [10, 11]. Due to their unique geometry, a decrease in the average grain size of the matrix can be observed, which translates into a significant increase in hardness. Furthermore, the GFM addition improves fracture toughness by introducing mechanisms such as delamination, crack bridging, deflection, and branching into ceramic matrix $[12,13]$.

MXene phases are one of the newest and most promising groups of $2 \mathrm{D}$ crystals. Their genesis dates back to the 
1970s, when the MAX phases, otherwise known as Nowotny's phases, were described $[14,15]$. Their name refers to their stoichiometry, which can be written as $M_{(n+1)} A X_{n}$, where $\mathrm{M}$ stands for a transition metal ( $\mathrm{Ti}, \mathrm{V}, \mathrm{Cr}, \mathrm{Nb}$ etc.), A is a group 13 or 14 metal ( $\mathrm{Al}, \mathrm{Si}$ etc.), $\mathrm{X}$ is nitrogen or carbon, and $n=1,2$ or 3 [16]. Depending on the number, the MAX phases may be divided into six groups: $\mathrm{M}_{2} \mathrm{AX}$ (phase 211), $M_{3} A X_{2}$ (phase 312), $M_{4} A_{3}$ (phase 413), $M_{5} A X_{4}$ (phase 514), $\mathrm{M}_{6} \mathrm{AX}_{5}$ (phase 615), and $\mathrm{M}_{7} \mathrm{AX}_{6}$ (phase 716) [17]. MAX phases form a laminated structure with high anisotropy properties. $M_{(n+1)} X_{n}$ layers with strong covalent bonds can be distinguished within them. These layers are connected with each other by much weaker metallic M-A bonds. A significant difference in the energy of these bonds caused the removal of group A atoms as a consequence of etching. This phenomenon allowed to obtain expanded 2D layers with a $\mathrm{M}_{(\mathrm{n}+1)} \mathrm{Xn}$ stoichiometry that are chemically and thermally stable [18]. These have been named MXene. The first attempt to conduct this type of process was described by Naquib et al. in 2011 [19]. Studies show that MXene phases, due to their unique electrical and chemical properties, show the potential for use in medicine [20-23], the construction of a new generation of energy storage [24-28], and for the creation of various types of sensors $[29,30]$. A number of researchers also raised the idea of using MXene phases as a reinforcement in the polymer-based composites nylon- 6 [31], polyurethane [32, 33], polyvinyl alcohol [34, 35] and polyvinylidene fluoride [36].

Moreover, MXene phases were successfully incorporated into a metallic matrix. A study [37] proved that a $3 \mathrm{wt} \%$ MXene addition improves the fracture toughness and tensile strength properties of alumina matrix by $92 \%$ and $50 \%$ respectively. An almost twofold decrease of the coefficient of friction was observed in the case of those composites. Guo et al. [38] presented hybrid epoxy resin matrix composites reinforced with MXene phases and nano-Al2O3. With these, a significant decrease of the wear rate was detected.

The chemical composition and geometry of MXene phases, similar to graphene, suggest that they may play the role of reinforcements in ceramic-based composites. However, the current state of the literature suggests that adequate research has not been conducted on this topic. The main issue in the case of introducing MXene phases into a ceramic matrix is the high temperature required for the sintering of dense composites, as well as interdiffusion and chemical reactions that can occur at the sintering temperature between the sintered composite's phases. In addition, as studies show, the MXene phases tend to degrade quickly in an oxygen environment, namely at temperatures above $300{ }^{\circ} \mathrm{C}$; whereas in an argon atmosphere, this threshold can be raised to 800 ${ }^{\circ} \mathrm{C}$ [39].

M. Fei et al. [40] made an attempt to obtain $\mathrm{Al}_{2} \mathrm{O}_{3}$ matrix composites reinforced with a $\mathrm{Ti}_{3} \mathrm{C}_{2} \mathrm{~T}_{\mathrm{x}}$ phase using pressureless sintering in air conditions. The analysis of mechanical properties allowed for an increase in fracture toughness, flexural strength, and hardness by $300 \%, 150 \%$, and $300 \%$, respectively, for the composites containing a 3 wt $\%$ addition of the MXene phase. Cygan et. al. [41], in turn, compared the influence of the $\mathrm{Ti}_{3} \mathrm{C}_{2}$ MXene phase and the $\mathrm{Ti}_{3} \mathrm{C}_{2}$ phase sputter coated with titanium and molybdenum on the microstructure and mechanical properties of $\mathrm{Al}_{2} \mathrm{O}_{3}$. They established that the presence of a metallic coating may notably change the form of degradation in the MXene phases. The composites with the addition of $\mathrm{Ti}_{3} \mathrm{C}_{2}$ coated with molybdenum exhibited an increase in hardness of almost $10 \%$ and an increase in fracture toughness of almost $15 \%$. Guo et. al [42] proposed an unconventional Cold Sintering Process (CSP), which assumes the use of a transient aqueous solution to produce dense $\mathrm{ZnO}-\mathrm{Ti}_{3} \mathrm{C}_{2}$ composites at temperatures below $300{ }^{\circ} \mathrm{C}$. An increase in hardness of nearly $50 \%$ was obtained for a $1 \mathrm{wt} \%$ additive, and nearly $150 \%$ for a $5 \mathrm{wt} \%$ additive. The elastic modulus was $30 \%$ and almost $100 \%$ higher (for $1 \mathrm{wt} \%$ and $5 \mathrm{wt} \%$ additives, respectively) than the one of the unreinforced $\mathrm{ZnO}$. An increase of 1-2 orders was observed for thermal conductivity for $\mathrm{ZnO}-5$ wt\% Ti3C2.Woźniak et. al. [43], in turn, describe the $\mathrm{SiC}$ composites with the addition of $\mathrm{Ti}_{2} \mathrm{C}$ phase sintered with the use of the Spark Plasma Sintering (SPS) method at a temperature of up to $1900{ }^{\circ} \mathrm{C}$, where the influence of the MXene phase on the improvement of mechanical properties was demonstrated despite the temperature significantly exceeding their thermal stability. The microstructure analysis showed the presence of flakes located at the boundaries of the grains, which were identified by the authors as $\mathrm{Ti}_{2} \mathrm{C}$ flakes. The same authors studied the influence of the $\mathrm{Ti}_{3} \mathrm{C}_{2}$ MXene phase on a silicon nitride matrix [44]. They did not detect any MXene phases in the final microstructure of the sinters. Nonetheless, a major influence of the $\mathrm{Ti}_{3} \mathrm{C}_{2}$ phase on the phase composition of the obtained sinters was observed. A $2 \mathrm{wt} \%$ addition of the MXene phase is enough for the phase transformation to be blocked, with a simultaneous creation of $\mathrm{Si}_{2} \mathrm{~N}_{2} \mathrm{O}$ phases. Ding et al. [45], in turn, proposed a method of obtaining MXene derived TiC/SiBCN ceramic materials for electromagnetic shielding. While heating the mixture of carbon-rich hyperbranched polyborosilazane precursor (hb-PBSZ) and $\mathrm{Ti}_{3} \mathrm{C}_{2} \mathrm{~T}_{\mathrm{x}}$ MXene, the forming titanium oxides react with carbon and produce titanium carbide.

There is a limited amount of research on the usage of MXene phases as a reinforcement in ceramic matrix composites which may constitute a basis for further studies. This article describes the attempts to produce silicon carbide matrix composites with the addition of the $\mathrm{Ti}_{3} \mathrm{C}_{2}$ phase using the Spark Plasma Sintering method and investigates the effect of its addition on microstructure and mechanical properties. A detailed analysis of the structure of the reinforcing phase after the sintering process was also carried out. 
It allowed for the identification of the mechanisms responsible for the influence of the MXene addition on the silicon carbide.

\section{Experiment}

\subsection{Substrates}

The powder used as a matrix was commercial $\beta$-SiC (Alfa Aesar, $99.8 \%$ chemical purity, $0.42 \mu \mathrm{m}$ average particle size). As sintering activators, amorphous boron powder (International Enzymes Limited, 96\% chemical purity, 0.39 $\mu \mathrm{m}$ average particles size) and synthetic graphite powder (Sigma Aldrich, 99\% chemical purity, average flake size below $20 \mu \mathrm{m}$ ) were used. $\mathrm{A} \mathrm{Ti}_{3} \mathrm{C}_{2}$ MXene phase was applied as a reinforcement. Spherical Carbon Black (Sigma Aldrich, 99\% chemical purity, average particles size below $100 \mathrm{~nm}$ ) was added as the sintering aid in the reference composite.

\section{2 $\mathrm{Ti}_{3} \mathrm{C}_{2}$ MXene preparation}

The $312 \mathrm{MAX}$ phase- $\mathrm{Ti}_{3} \mathrm{AlC}_{2}$ was synthetized with the use of the self-propagating high-temperature synthesis technique (SHS). A detailed description of this method was included in the study [46]. In short, the synthesis was carried out using SHS-derived $\mathrm{Ti}_{3} \mathrm{Al}$ (aluminum powder: AEE, 99\% chemical purity, particle size -325 mesh; titanium powder: AEE, 99.9\% chemical purity, particle size -325 mesh) and graphite (Merck no. 1.04206.9050, 99.8\% chemical purity, average particle below $50 \mu \mathrm{m}$ ) as substrates. The substrates reacted in stoichiometric proportions according to the equation:

$\mathrm{Ti}_{3} \mathrm{Al}+2 \mathrm{C} \rightarrow \mathrm{Ti}_{3} \mathrm{AlC}_{2}$.

$125 \mathrm{~g}$ of the homogenized powder mixture was placed in the chamber and ignited (local ignition system). The ignition time was $60 \mathrm{~s}$. Following that, the self-sustaining process was continued until the substrates were consumed. After cooling, the product of the synthesis was ground $(8 \mathrm{~h}$ grinding, rotary-vibratory mill, WC balls, isopropanol).

For obtaining the $\mathrm{Ti}_{3} \mathrm{C}_{2}$ MXene phase, the expanding and delamination processes were carried out on the MAX phase. For that purpose, the $\mathrm{Ti}_{3} \mathrm{AlC}_{2}$ powder was added to hydrofluoric acid (48 wt.\% in water solution) in the amount of $1 \mathrm{~g}$ of MAX phase per $10 \mathrm{ml}$. The suspension was stirred with a magnetic bar for $24 \mathrm{~h}$. After sedimentation and decanting of the suspension, the washing process with deionized water and ethanol was performed. Subsequently, the two-step process of delamination with the use of ultrasound probe sonication (Vibra Cell, VCX750) took place. First, the expanded $\mathrm{Ti}_{3} \mathrm{C}_{2}$ was dispersed in hexane ( $1 \mathrm{~g}$ MAX phase per $\left.50 \mathrm{ml}\right)$. Then, the sonication process was conducted in an inert gas atmosphere and an ice bath for $2 \mathrm{~h}(520 \mathrm{~W}$ power, $1 \mathrm{~s}$ Pulse $\mathrm{ON}, 3 \mathrm{~s}$ pulse $\mathrm{OFF}$ ). In the second stage, after decantation and drying, the process of delamination was repeated and dry propan-2-ol was used instead of hexane. The ratio of the powder to the dispersing medium and the conditions were the same as before, but the duration of the process was half as long ( $1 \mathrm{~h}, 1 \mathrm{~s}$ pulse $\mathrm{ON}, 3 \mathrm{~s}$ pulse $\mathrm{OFF})$. The suspension was then centrifuged for $2 \mathrm{~min}$ at $2500 \mathrm{rpm}$. The sediment of $\mathrm{Ti}_{3} \mathrm{C}_{2}$ MXene was dried for $6 \mathrm{~h}$ at $23{ }^{\circ} \mathrm{C}$ and then stored for further use at $50{ }^{\circ} \mathrm{C}$ in an argon atmosphere.

\section{$2.3 \mathrm{Ti}_{3} \mathrm{C}_{2}$ characterization}

The surface morphology and the shape of particles of $\mathrm{Ti}_{3} \mathrm{C}_{2}$ MXene 2D sheets were investigated with the use of a scanning electron microscope (SEM, LEO 1530, Zeiss, USA). The structure of $\mathrm{Ti}_{3} \mathrm{C}_{2}$ was analyzed using a transmission electron microscope. The surface chemistry of the obtained $\mathrm{Ti}_{3} \mathrm{C}_{2}$ phase sheets was analyzed using an X-ray photoelectron spectroscopy (XPS). For this purpose, a PHI 5000 VersaProbe (ULVAC-PHI, Kanagawa, Japan) spectrometer with monochromatic $\mathrm{Al} \mathrm{K} \alpha$ radiation was used.

\section{4 $\mathrm{SiC}-\mathrm{Ti}_{3} \mathrm{C}_{2}$ composites manufacturing}

$\mathrm{SiC}-\mathrm{x} \mathrm{Ti}_{3} \mathrm{C}_{2}$ composites (where $x=0.2,0.5,0.7,1,1.5,2$, 2.5, $3 \mathrm{wt} \%$ ) were obtained through the powder metallurgy technique and sintered with the use of the Spark Plasma Sintering method. Based on the previous optimization work [47], the amount of sintering aids, i.e., boron and carbon, was $0.3 \mathrm{wt} \%$ and $1 \mathrm{wt} \%$, respectively. The prepared powder mixtures were homogenized in a planetary mill (Fritsch PULVERISETTE 5/4, Germany) for $10 \mathrm{~h}$ in an isopropyl alcohol suspension. Corundum balls were used as a grinding aid (10 $\mathrm{g}$ of grinding balls per $1 \mathrm{~g}$ of powder mixture). After drying $\left(T=50^{\circ} \mathrm{C}\right)$ and sieving $(\# 300 \mu \mathrm{m})$ the cylindrical samples $(d=20 \mathrm{~mm}, H=3 \mathrm{~mm})$ were consolidated in a vacuum $\left(5 \times 10^{-2} \mathrm{~m}\right.$ bar $)$ with the use of SPS. The applied sintering conditions were as follows: sintering temperature: $1900{ }^{\circ} \mathrm{C}$, heating rate: $100{ }^{\circ} \mathrm{C} / \mathrm{min}$, dwell time: $30 \mathrm{~min}$, applied force: $16 \mathrm{kN}$. Some changes in the microstructure and mechanical properties were connected with the reinforcing phase used. A pure $\mathrm{SiC}$ with the addition of only $1 \mathrm{wt} \%$ of graphite and $0.3 \mathrm{wt} \%$ of boron was sintered to thoroughly analyze this. With the purpose of identifying the flakes present in the microstructure, $\mathrm{SiC}$ with $2 \mathrm{wt} \%$ of $\mathrm{Ti}_{3} \mathrm{C}_{2}, 0.5 \mathrm{wt} \%$ of carbon black instead of graphite and $0.3 \mathrm{wt} \%$ of boron were sintered as the reference composite.

\section{5 $\mathrm{SiC}-\mathrm{Ti}_{3} \mathrm{C}_{2}$ composites characterization}

The density of the specimens was examined using the Archimedes method (Standard number: PN-76/B-06714/05), 
whereas hardness and fracture toughness were measured with the Vickers Hardness Tester (FV-700e, Future Tech, Kawasaki-City, Japan) using the indentation method under a load of $49.05 \mathrm{~N}$. To determine the mechanical properties of the ceramics, the tests were carried out on three samples of the obtained composites. 20 hardness measurements and 12 crack length measurements were made for each sample. The microstructure observations were performed on a scanning electron microscope (SEM 5500, Hitachi, Tokyo, Japan). On the basis of the obtained images, the average equivalent grain diameter was determined (NIS-elements software was used). The qualitative phase composition of the obtained sinters was analyzed with the use of XRD diffraction (Bruker Corporation, Billerica, MA, USA) with $\mathrm{Cu}$ $\mathrm{K} \alpha(\lambda=0.154056 \mathrm{~nm})$ radiation. The recording was made in the angular range of $2 \theta$ angle from $10^{\circ}$ to $110^{\circ}$ with a step of $2 \theta-0.05^{\circ}$ and a counting time of $3 \mathrm{~s}$. The elemental mapping was performed using a scanning electron microscope with an EDS display. Scanning transmission electron microscopy images and diffraction patterns were obtained on an FEI Tecnai G2 F20 S-TWIN microscope (Oregon, USA), operating at $200 \mathrm{kV}$ and equipped with a Fischione 3000 high angle annular dark field (HAADF) STEM detector.

\section{Results}

The characterization of $\mathrm{Ti}_{3} \mathrm{C}_{2}$ MXene used as the reinforcement is presented in Fig. 1. Figure 1a, b shows the morphology of expanded $\mathrm{Ti}_{3} \mathrm{C}_{2}$ MXene phases and multilayered 2D flakes of $\mathrm{Ti}_{3} \mathrm{C}_{2}$, respectively. These figures present how individual layers separate and spread, creating a loosely packed stack. This phenomenon is the effect of the reaction of the MAX phase with hydrofluoric acid, which has etched the aluminum atoms. The use of the sonication process contributed to the separation of these layers, whereby $2 \mathrm{D} \mathrm{Ti}{ }_{3} \mathrm{C}_{2}$ flakes were obtained (Fig. 1b). The presence of the Tyndall effect clearly shows that the obtained $\mathrm{Ti}_{3} \mathrm{C}_{2}$ MXene sheets
Fig. 1 The morphology of a $\mathrm{Ti}_{3} \mathrm{C}_{2}$ MXene after etching and b delaminated $2 \mathrm{D} \mathrm{Ti}_{3} \mathrm{C}_{2}$ MXene phase accompanied with Tyndall test, c Cross-sectional HRTEM observations of the multilayered structure of the individual 2D $\mathrm{Ti}_{3} \mathrm{C}_{2}$ MXene sheets, $\mathbf{d}$ The intensity pattern revealing a period related to d-spacing of $0.9 \mathrm{~nm}$, e results of EDX analysis $\mathbf{f}$ curved-fitted XPS spectrum related to Ti2p, g curved-fitted XPS spectrum related to $\mathrm{O} 1 \mathrm{~s}$
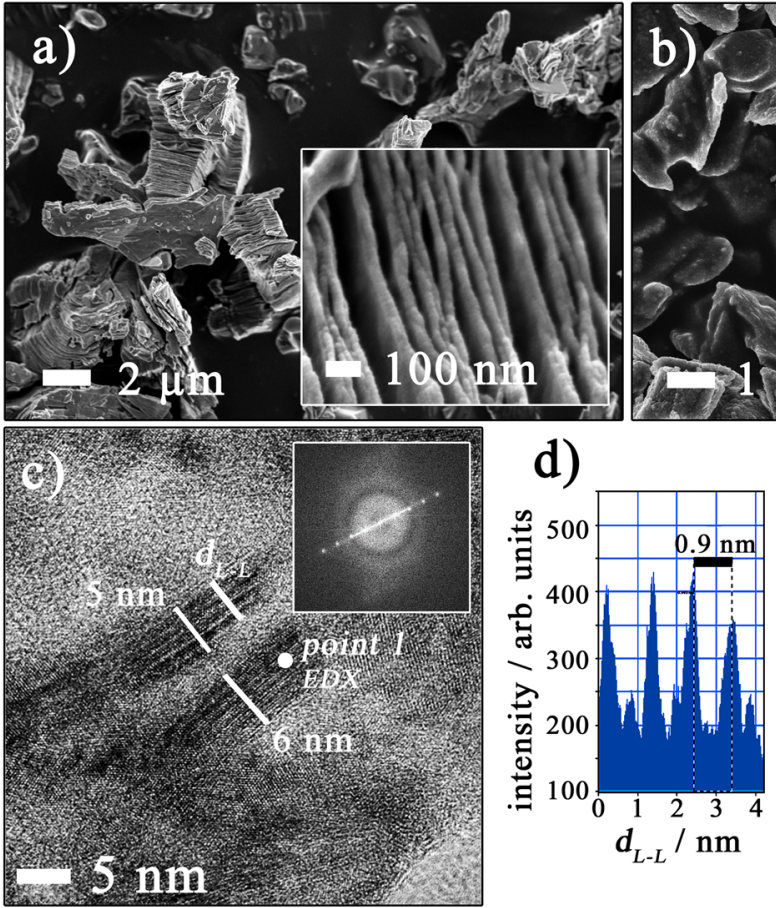

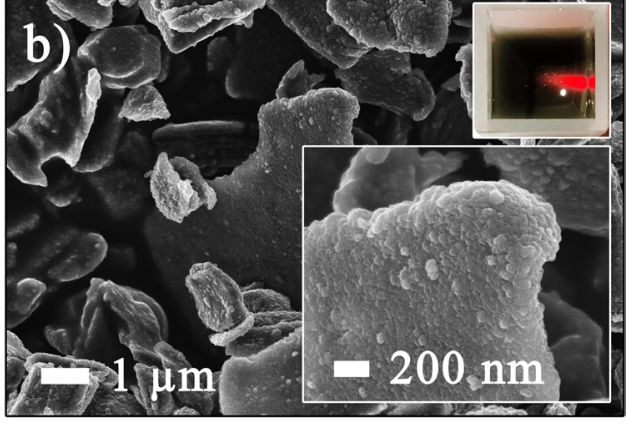

e)

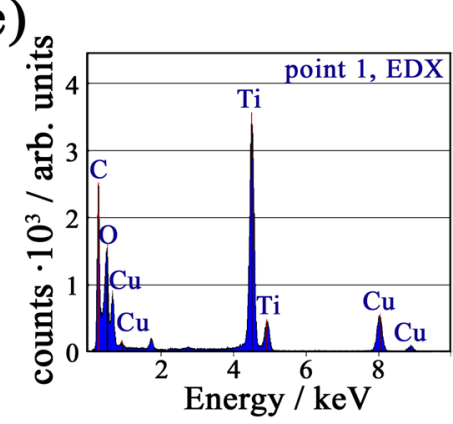

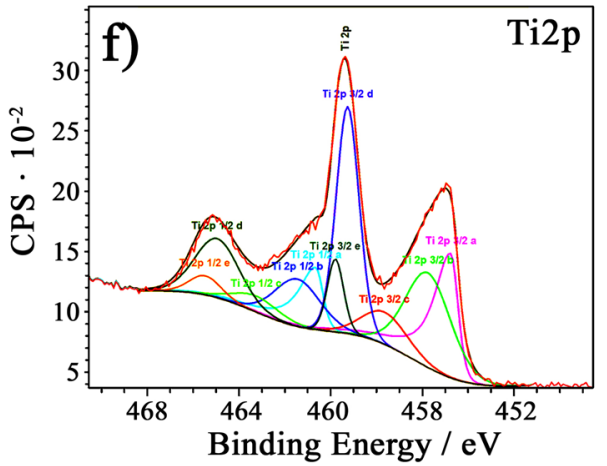

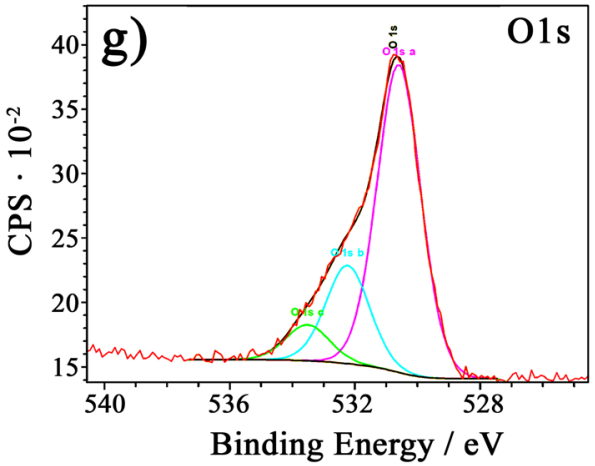


formed a stable colloidal solution in deionized water (upper insert in Fig. 1b). Figure 1c-e presents the TEM analysis of the $\mathrm{Ti}_{3} \mathrm{C}_{2}$ phase. The thickness of individual $\mathrm{Ti}_{3} \mathrm{C}_{2}$ flakes varies by around a few nanometres (Fig. 1c, d), whereas the $\mathrm{d}$-spacing for $-\mathrm{Ti}_{3} \mathrm{C}_{2}-\mathrm{Ti}_{3} \mathrm{C}_{2}-\mathrm{Ti}_{3} \mathrm{C}_{2}-$ period is $0.9 \mathrm{~nm}$. This corresponds well with the results of other research obtained for the multilayered $\mathrm{Ti}_{3} \mathrm{C}_{2}$ [48]. A chemical composition analysis of the produced crystals revealed the presence of copper and oxygen (Fig. 1e), in addition to titanium and carbon. The presence of copper is associated with the preparation of the sample, while oxygen suggests the existence of functional groups on the flakes' surfaces. This fact is also supported by the presence of extremely small particles observed on the surface of delaminated flakes (Fig. 1b).To verify this observation, the delaminated $\mathrm{Ti}_{3} \mathrm{C}_{2}$ flakes were subjected to an XPS analysis. The deconvoluted XPS spectra were presented in Fig. 1f, g. The results of these experiments revealed the presence of a Ti2p signal (Fig. 1f) in the range of binding energy from 454.7 to 465.2 which confirmed the occurrence of $\mathrm{Ti}-\mathrm{C}$ and $\mathrm{Ti}-\mathrm{O}$ bonds. This indicates that the small surface particles may be identified as titanium dioxide $\left(\mathrm{TiO}_{2}\right)$ of both a crystalline and amorphous form. In turn, the spectrum presented in Fig. $1 \mathrm{~g}$ indicates the presence of $\mathrm{C}-\mathrm{O}$ and $\mathrm{C}=\mathrm{O}$ bonds. This type of functional group is also characteristic for the MXene phases [19].

The influence of the delaminated $2 \mathrm{D} \mathrm{Ti}_{3} \mathrm{C}_{2}$ phase addition on the physical and mechanical properties of the obtained composites is presented in Table 1. As can be observed, the addition of $0.2 \mathrm{wt} \% \mathrm{Ti}_{3} \mathrm{C}_{2}$ results in a minimal increase in relative density to the level of $99.5 \%$. A slow decrease in relative density, reaching the level of the reference sample (98.4\%) is observed for the composite with the $1 \mathrm{wt} \%$ addition of $\mathrm{Ti}_{3} \mathrm{C}_{2}$. Increasing the amount of the MXene phase does not further increase nor decrease the relative density, which fluctuates from $1 \mathrm{wt} \%$ to $3 \mathrm{wt} \%$ of $\mathrm{Ti}_{3} \mathrm{C}_{2}$ in the area of $98.5 \%$.

An increase of hardness with the increasing content of $\mathrm{Ti}_{3} \mathrm{C}_{2}$, from $20.7 \mathrm{GPa}$ for pure sinter to $23.5 \mathrm{GPa}$ for composites with $1.5 \mathrm{wt} \%$ of $\mathrm{Ti}_{3} \mathrm{C}_{2}$ addition can be observed.
After exceeding this content, a systematic drop in the average hardness to the level of $21 \mathrm{GPa}$ occurs. It is worth noting that in composites with the higher amount of $\mathrm{Ti}_{3} \mathrm{C}_{2}(1.5$ $\mathrm{wt} \%$ and above), high error bars indicating a large spread of measured values may be observed.

In the case of fracture toughness, its highest value was obtained for the $0.2 \mathrm{wt} \%$ addition. The increase was over $50 \%$ higher in comparison with pure silicon carbide. The values amounted to 3.1 for the pure sinter and 4.65 for the $0.2 \mathrm{wt} \%$ of $\mathrm{Ti}_{3} \mathrm{C}_{2}$ addition. Following that, along with the increase in the content of the $\mathrm{Ti}_{3} \mathrm{C}_{2}$, fracture toughness, similarly to hardness, slowly but steadily drops down to a level close to the reference sample.

The description of the composites has been supplemented with a stereological analysis (Table 1). A decrease of average grain size, even for small additions of the reinforcing phase, can be observed. The calculated average equivalent diameter decreased from $0.99 \mu \mathrm{m}$ for pure $\mathrm{SiC}$ to $0.72 \mu \mathrm{m}$ for $\mathrm{SiC}$ with a $0.5 \mathrm{wt} \%$ addition of $\mathrm{Ti}_{3} \mathrm{C}_{2}$. After exceeding $0.5 \mathrm{wt} \%$ of $\mathrm{Ti}_{3} \mathrm{C}_{2}$ addition, the average grain size stabilized at a constant level oscillating around $0.73 \mu \mathrm{m}$ for the entire analyzed range. A similar phenomenon has been reported by other authors in the case of graphene family materials reinforced ceramic composites [49] or silicon carbide composites reinforced with a $2 \mathrm{D}-\mathrm{Ti}_{2} \mathrm{C}$ phase [43].

A thorough microstructure analysis was carried out to accurately characterize the produced composites and the mechanisms responsible for the impact of the addition of MXene phases on the change in the mechanical properties of the composites. The analysis included fracture surface observations (Fig. 2) and phase composition analysis (Fig. 3). A homogeneous microstructure in terms of the grain's shape and size can be observed for all composites. For a small addition of the MXene phase, a few-layer flake located on grain boundaries may be noticed (Fig. 3a). Their shape and geometry correspond to the shape and geometry of the $\mathrm{Ti}_{3} \mathrm{C}_{2}$ flakes used (Fig. 1a, b). The presented pictures show that the flakes are characterized with a strong bond to the matrix. The interface is devoid of
Table 1 Relative density, average grain size, hardness and fracture toughness of the obtained composites

\begin{tabular}{lllll}
\hline Material & Relative density [\%] & $\begin{array}{l}\text { Average grain } \\
\text { size }[\mu \mathrm{m}]\end{array}$ & Hardness [GPa] & $\begin{array}{l}\text { Fracture tough- } \\
\text { ness [MPa*0.5] }\end{array}$ \\
\hline $\mathrm{SiC}$ & $98.4 \pm 0.24$ & $0.99 \pm 0.04$ & $20.7 \pm 0.4$ & $3.1 \pm 0.2$ \\
$\mathrm{SiC}+0.2 \mathrm{wt} \% \mathrm{Ti} 3 \mathrm{C} 2$ & $99.5 \pm 0.20$ & $0.72 \pm 0.02$ & $20.4 \pm 0.3$ & $4.5 \pm 0.3$ \\
$\mathrm{SiC}+0.5 \mathrm{wt} \% \mathrm{Ti}_{3} \mathrm{C}_{2}$ & $99.1 \pm 0.34$ & $0.73 \pm 0.03$ & $21.5 \pm 0.3$ & $4.3 \pm 0.3$ \\
$\mathrm{SiC}+0.7 \mathrm{wt} \% \mathrm{Ti}_{3} \mathrm{C}_{2}$ & $98.6 \pm 0.41$ & $0.73 \pm 0.03$ & $21.7 \pm 0.4$ & $4.4 \pm 0.2$ \\
$\mathrm{SiC}+1 \mathrm{wt} \% \mathrm{Ti}_{3} \mathrm{C}_{2}$ & $98.4 \pm 0.21$ & $0.72 \pm 0.05$ & $22.7 \pm 0.4$ & $4.2 \pm 0.3$ \\
$\mathrm{SiC}+1.5 \mathrm{wt} \% \mathrm{Ti}_{3} \mathrm{C}_{2}$ & $98.1 \pm 0.34$ & $0.75 \pm 0.04$ & $23.2 \pm 0.4$ & $3.9 \pm 0.5$ \\
$\mathrm{SiC}+2 \mathrm{wt} \% \mathrm{Ti}_{3} \mathrm{C}_{2}$ & $98.4 \pm 0.43$ & $0.71 \pm 0.03$ & $22.4 \pm 1.0$ & $4.0 \pm 0.4$ \\
$\mathrm{SiC}+2.5 \mathrm{wt} \% \mathrm{Ti}_{3} \mathrm{C}_{2}$ & $98.5 \pm 0.38$ & $0.72 \pm 0.03$ & $21.5 \pm 1.0$ & $3.3 \pm 0.4$ \\
$\mathrm{SiC}+3 \mathrm{wt} \% \mathrm{Ti}_{3} \mathrm{C}_{2}$ & $98.4 \pm 0.41$ & $0.73 \pm 0.06$ & $21.2 \pm 0.6$ & $3.2 \pm 0.6$ \\
\hline
\end{tabular}



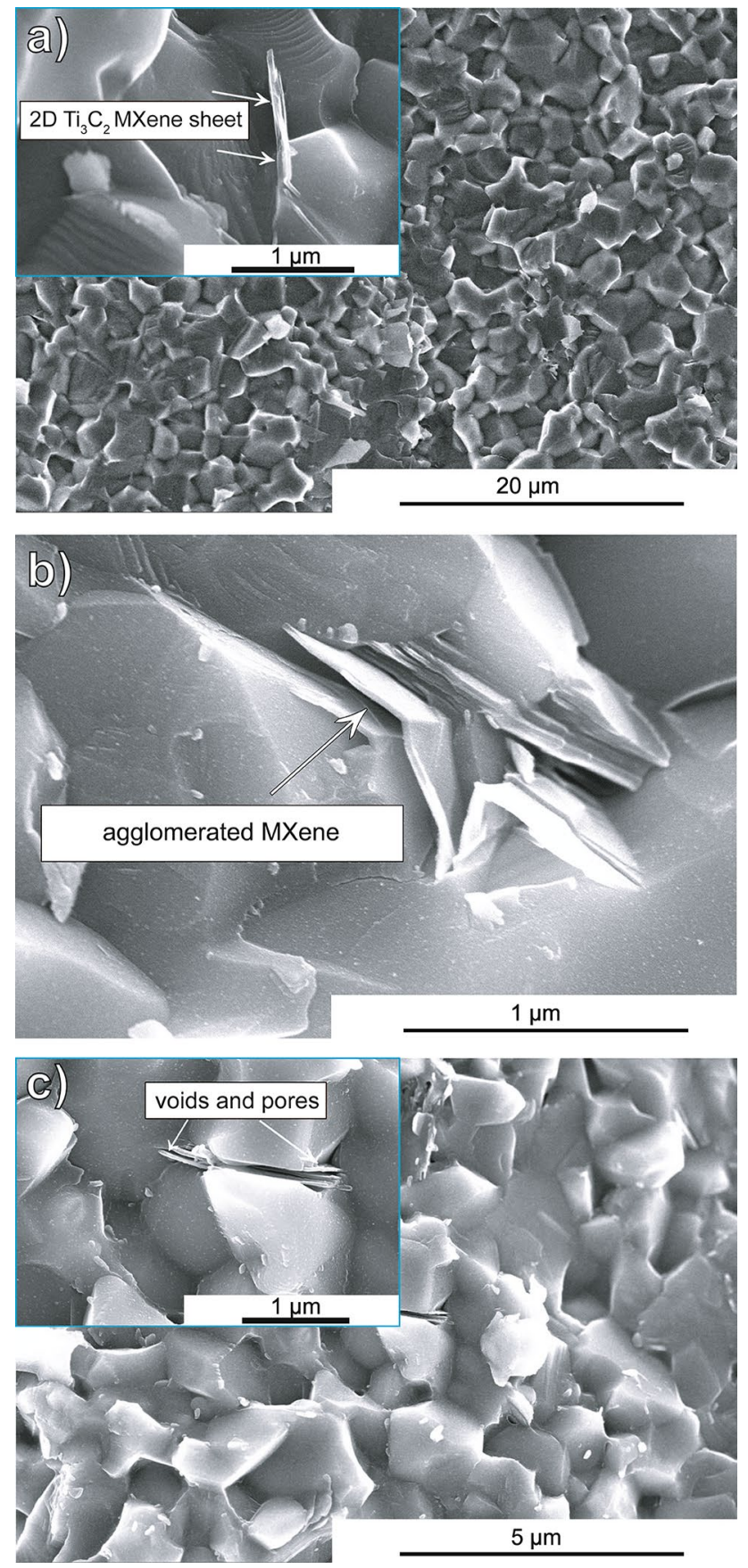

Fig. 2 Fracture surface of the obtained composites a $\mathrm{SiC}+0.7 \mathrm{wt} \%$ of $\mathrm{Ti}_{3} \mathrm{C}_{2}, \mathbf{b ~ S i C}+2.5 \mathrm{wt} \%$ of $\mathrm{Ti}_{3} \mathrm{C}_{2}$ and $\mathbf{c ~ S i C}+3 \mathrm{wt} \%$ of $\mathrm{Ti}_{3} \mathrm{C}_{2}$

pores, voids, and discontinuities. Its character changes with the increase of $\mathrm{Ti}_{3} \mathrm{C}_{2}$ content. For the $\mathrm{SiC}$ with the 2.5 $\mathrm{wt} \%$ and $3 \mathrm{wt} \%$ additions of $\mathrm{Ti}_{3} \mathrm{C}_{2}$ (Fig. $2 \mathrm{~b}$, c respectively) flakes of much higher thickness can be observed. This is accompanied by the appearance of voids and pores within the flakes. This analysis suggests that the observed flakes may be identified as $\mathrm{Ti}_{3} \mathrm{C}_{2}$ flakes. However, this conclusion was not confirmed by the results of the phase composition

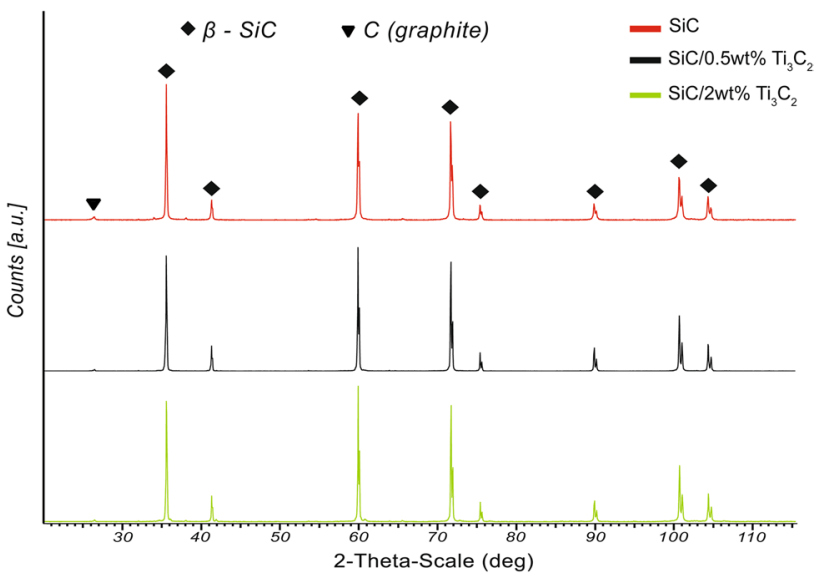

Fig. 3 The XRD results of the obtained composites

test presented in Fig. 3. The position of XRD peaks and almost identical XRD pattern for all tested samples confirmed single-phase compositions in the case of both the pure $\mathrm{SiC}$ sinter, and the produced composites. Apart from $\beta$-SiC and trace amounts of carbon, the $\mathrm{Ti}_{3} \mathrm{C}_{2}$ phase was not found in any of the tested composites [50].

Due to incomplete information on the structure of the observed flakes, an elemental mapping analysis was performed using the EDS technique (Fig. 4). Figure $4 \mathrm{a}$, b presents the areas analyzed for the $\mathrm{SiC}+2 \mathrm{wt} \%$ of $\mathrm{Ti}_{3} \mathrm{C}_{2}$ composite. The microscopic analysis revealed the presence of two-layer structures in the material. One of them, shown in Fig. 4a, is of a significant width, exceeding $10 \mu \mathrm{m}$. The elemental map analysis has shown that these structures are built with carbon, which, in combination with their layering, allows one to recognize them as graphite. Their shape and size, combined with the absence of titanium within the carbon structure, suggests that this is the residue of graphite used as a sintering aid. The layered structures shown in Fig. $4 \mathrm{~b}$ began to appear more often, characterized by significantly smaller dimensions (approx. $1-5 \mu \mathrm{m}$ in length). A chemical composition analysis confirmed that the mentioned structures consist mainly of carbon. In relation to graphite structures (Fig. 4a), titanium was found within them. As a reference sample, $\mathrm{SiC}$ sinter with a $2 \mathrm{wt} \%$ content of $\mathrm{Ti}_{3} \mathrm{C}_{2}$ was produced and subjected to analysis, whereas spherical carbon black $(0.5 \mathrm{wt} \%)$ was used as the carbon source instead of graphite. As previous studies have shown [47], its addition in this amount ensures a high densification of silicon carbide and does not leave carbon structures in the microstructure after sintering. As can be seen in Fig. 4c, in this case layered structures are also observed, which, as shown by elemental map analysis, are made mainly of carbon. Similar to the structures observed in the $\mathrm{SiC}+2 \mathrm{wt} \%$ of $\mathrm{Ti}_{3} \mathrm{C}_{2}$ with graphite addition (Fig. $4 \mathrm{~b}$ ), areas rich in titanium 
Fig. 4 SEM image and energydispersive X-ray spectroscopy (EDS) maps of a polished crosssection of the composites a and b $\mathrm{SiC}+2 \mathrm{wt} \%$ of $\mathrm{Ti}_{3} \mathrm{C}_{2}$ with graphite as a sintering aid, $\mathbf{c}$ $\mathrm{SiC}+3 \mathrm{wt} \%$ of $\mathrm{Ti}_{3} \mathrm{C}_{2}$ with carbon black as a sintering aid
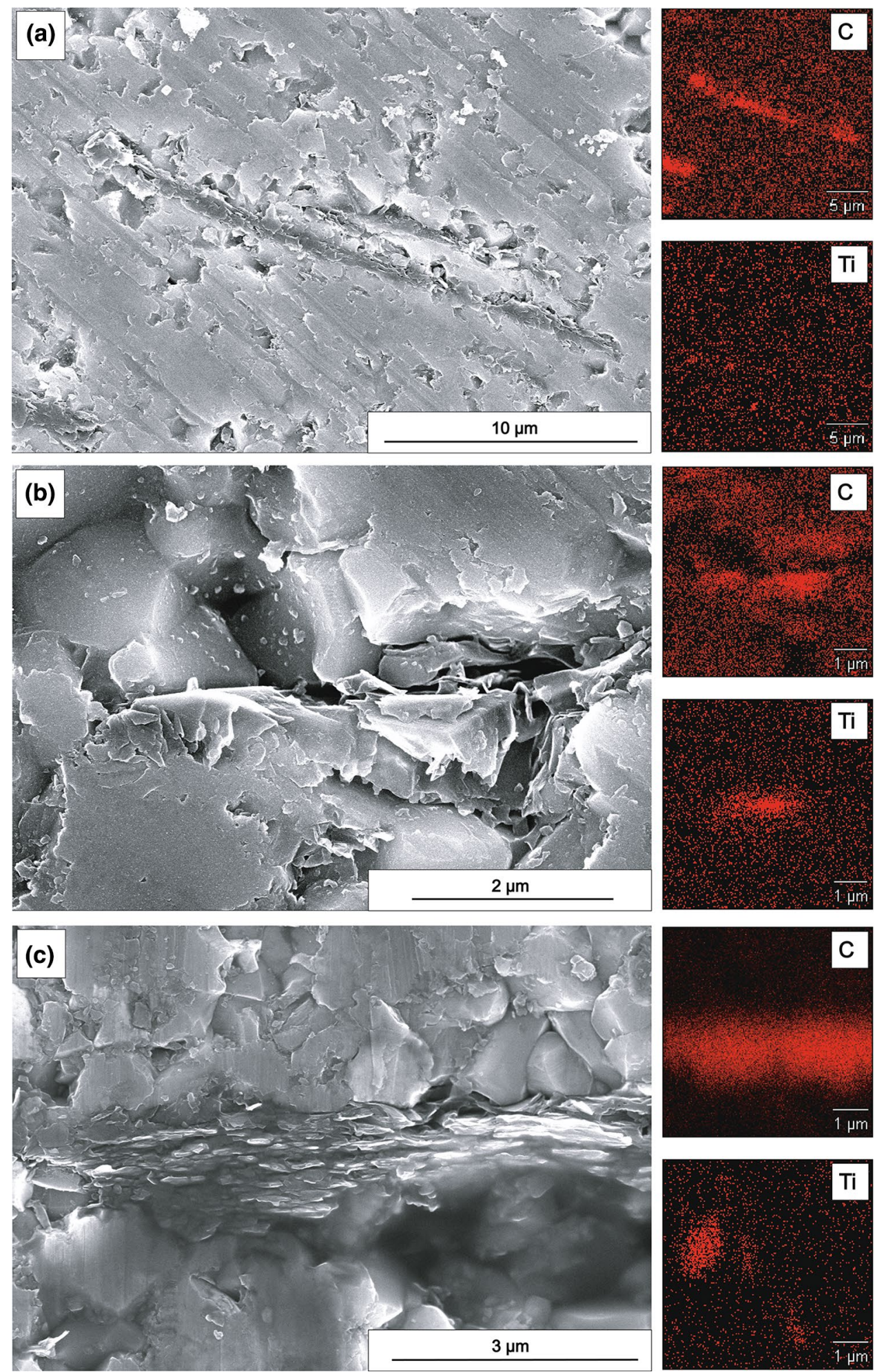

were found in their surroundings. In both cases, carbon and titanium-rich areas did not coincide.

The above analysis has been supplemented with TEM analysis. $\mathrm{SiC}+2 \mathrm{wt} \%$ of $\mathrm{Ti}_{3} \mathrm{C}_{2}$ with the addition of graphite (Fig. 5) and $\mathrm{SiC}+2 \mathrm{wt} \%$ of $\mathrm{Ti}_{3} \mathrm{C}_{2}$ with the addition of carbon black (Fig. 6) were subjected to testing. Figure 5a depicts an exemplary picture of the microstructure. Electron diffraction has confirmed the presence of only the SiC- $\beta$ phase, whereas $\mathrm{SiC}$ are the only grains visible. In Fig. 5b the HAADF-STEM image of a reinforcement phase particle 
Fig. 5 TEM analysis: a TEM Bright Field of the microstructure of $\mathrm{SiC} /$ Graphite/2wt\% $\mathrm{Ti}_{3} \mathrm{C}_{2}$ and electron diffraction of matrix grains, $\mathbf{b}$ STEM image of the reinforcing phase c HRTEM image of the area 1 and Fourier transform, $\mathbf{d}$ HRTEM image of the area 2 and Fourier transform
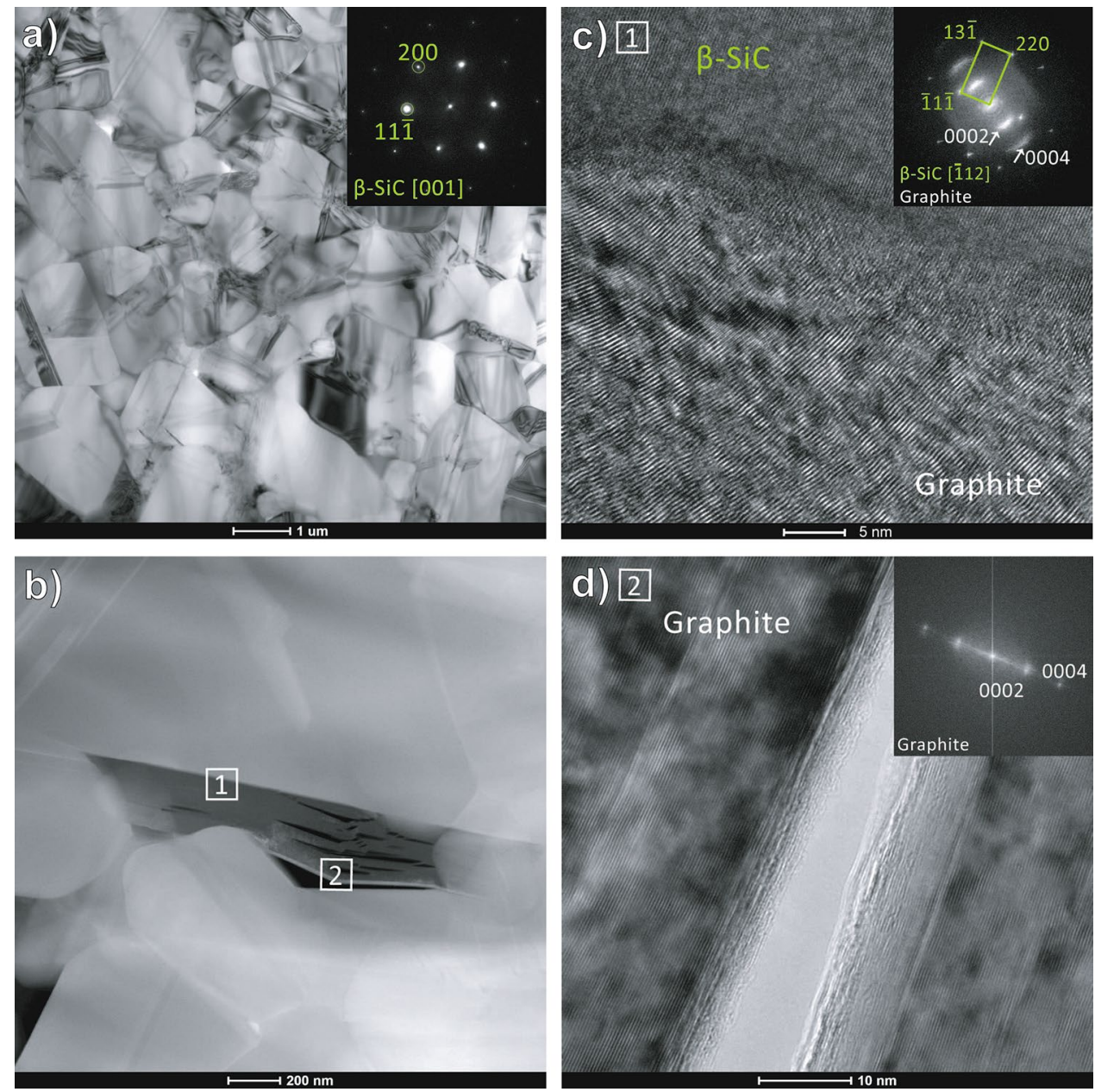

placed between the SiC grains was shown. The intensity of the HAADF signal is roughly proportional to the square of the average atomic number $\left(\mathrm{Z}^{2}\right)$ of the tested area and the thickness of the specimen (mass-thickness contrast). Local variations in the specimen's thickness are usually negligible, hence the higher intensity of the grains in the HAADF image suggests that they consist of heavier elements than the reinforcement phase. More than 2 types of interface have also been observed. Either the reinforcement phase was strongly adhering to the $\mathrm{SiC}$ grains (area 1) or small pores present between the reinforcement and the $\mathrm{SiC}$ grains (area 2) were noted. A significantly greater number of areas characterized with proper cohesion than the porous ones has been observed. Figure 5c presents the HRTEM image of the reinforcement phase/SiC interface taken along the [112] zone axis of the $\mathrm{SiC}$ grain. Fourier transform (FFT) shows spots arising from both the silicon carbide and reinforcement phase. The latter corresponds to a d-spacing of $3.40 \AA$ and $1.68 \AA$ which is consistent with the (0002) and (0004) reflections of graphite, respectively. The graphite planes deformed, which is also reflected in FFT as the spots are arc-shaped. The visible interface does not entail any pores, discontinuities, nor voids. Figure 5d presents the HRTEM picture of area 2, where voids and pores were detected. In this case, graphite layers are mutually parallel with no signs of deformation or spots instead of arcs visible in FFT (double spots are caused by a small misalignment of different parts of delaminated graphite). All of the layered structures present in the microstructure were identified as graphite.

Figure 6 presents the TEM analysis results for the $\mathrm{SiC}+2$ wt $\%$ of $\mathrm{Ti}_{3} \mathrm{C}_{2}$ composites with carbon black as the sintering aid, whereas Fig. 6a depicts a flake of reinforcement phase located between the matrix grains. Selected area electron diffraction (SAED) has confirmed that the observed phase is graphite. The diffraction pattern along with the HRTEM image taken from the same place and the corresponding FFT (Fig. 6b) have shown that graphite was significantly deformed. The defects are visible both as the delamination of certain areas and the bending of individual graphite sheets. The interplanar spacing between (0002) graphite planes of all structures oscillates around $0.340 \pm 0.1 \mathrm{~nm}$. Figure $6 \mathrm{c}$ shows the TEM BF image of the $\mathrm{SiC}$ grain adjacent to the graphite structures. The HRTEM image of the reinforcement phase/SiC interface (Fig. 6d) along with the FFT of 
Fig. 6 TEM analysis: a TEM Bright Field of the microstructure of $\mathrm{SiC} / \mathrm{CB} / 2 \mathrm{wt} \%$ $\mathrm{Ti}_{3} \mathrm{C}_{2}$ and electron diffraction of matrix grains, $\mathbf{b}$ HRTEM image of the reinforcing phase, c TEM Bright Field of the $\mathrm{SiC}$ grain and adjacent graphite, $\mathbf{d}$ HRTEM image of the area 1 and Fourier Transform
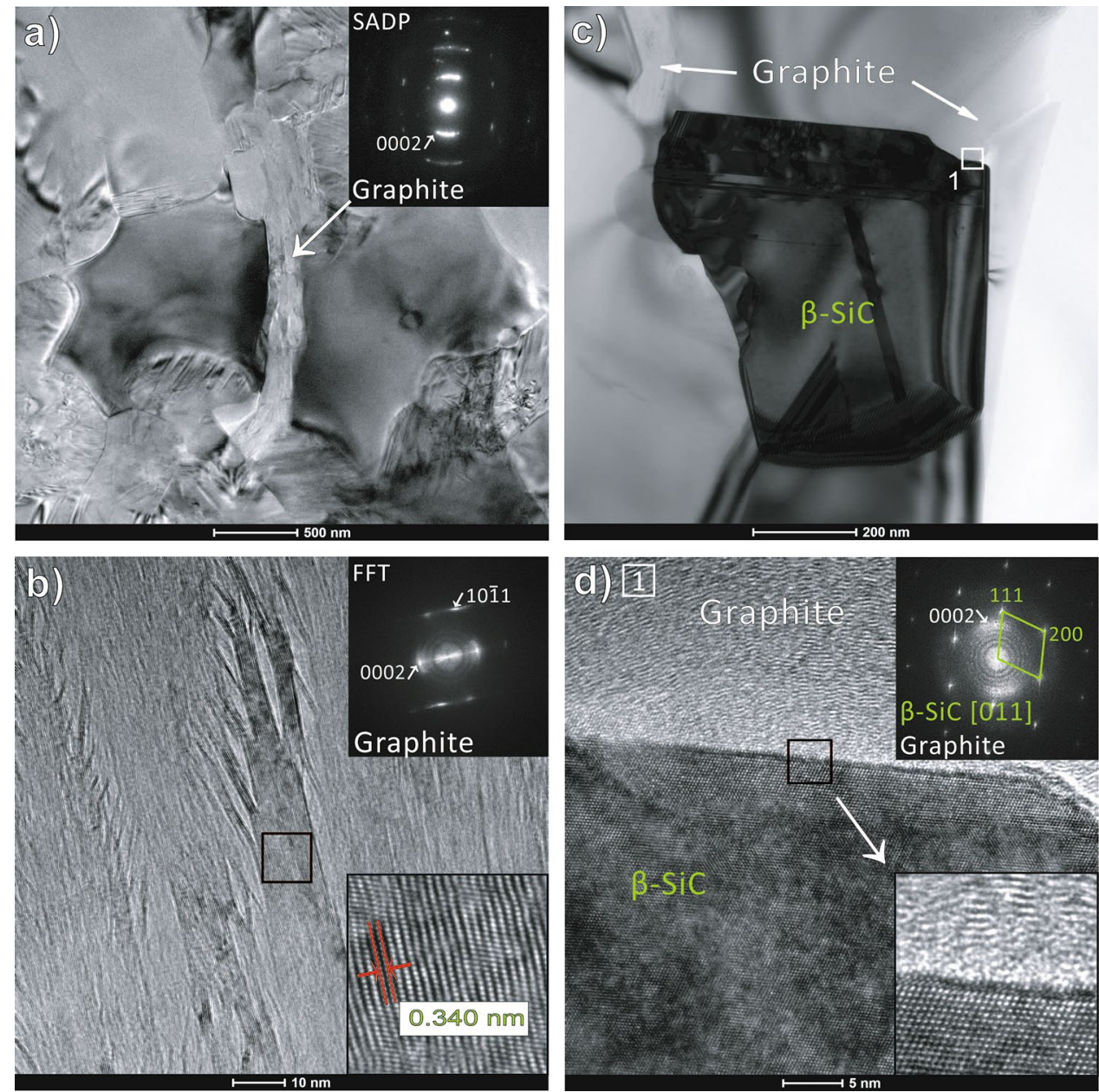

the entire area confirms the presence of graphite planes. The spots (0004) and arc-shaped lines (0002) suggest major graphite defects nearby the interface with matrix grains. It is worth emphasizing that the interface itself does not contain any voids nor pores. Graphite flakes strongly adhere to the matrix, and silicon carbide planes connect to graphite planes with no transitional layer visible.

\section{Discussion}

The analysis of the mechanical properties of the obtained $\mathrm{SiC}-\mathrm{Ti}_{3} \mathrm{C}_{2}$ composites presented in this work unambiguously suggests that the addition of an MXene phase allows one to considerably enhance the mechanical properties of a ceramics matrix. The microscopic observations of fracture surfaces confirm the presence of another phase located on the grains' boundaries. Its shape and size suggest that it appeared as the effect of adding the $\mathrm{Ti}_{3} \mathrm{C}_{2}$ phase. Moreover, this phase may be the cause of the observed increase of hardness and fracture toughness.
To thoroughly understand the mechanism responsible for the increase of mechanical properties, the above-mentioned structures were subjected to a detailed analysis. As the EDS elemental mapping indicated (Fig. 4b), all of the flakes with geometry conforming to $\mathrm{Ti}_{3} \mathrm{C}_{2}$ flakes consist predominantly of carbon. Small accumulations of titanium may be noticed within them, which points out to their origin. Areas rich in carbon and titanium do not fully correspond to each other, which does not indicate a $\mathrm{Ti}_{3} \mathrm{C}_{2}$ stoichiometry. The presence of carbon structures, with morphology corresponding to one of MXene phase, surrounded with small accumulates of titanium were also detected during the mapping process of the EDS composite. Carbon Black was used as an addition in the aforementioned process with the purpose of eliminating the remnants of graphite used as a sintering aid. The TEM analysis showed that the aforementioned structures are characterized with a hexagonal structure and planar spacings corresponding to those of graphite. The presence of a considerable amount of graphite flakes was detected both in the case of composites with the addition of carbon black and those with the addition of graphite. No other phases apart from $\beta$-SiC were detected. That fact, combined with 
trace amounts of carbon in the case of composites with the graphite addition leads to the conclusion that MXene phases may undergo transformation during the process of sintering, causing the creation of graphite. The conclusions that arise from the analysis of the SEM results and the TEM observations are supported by the XRD results. They confirm the lack of phases other than $\beta$-SiC and the presence of some traces of graphite in the final microstructure. Moreover, it is also worth noting that the addition of MXene phases did not affect the $\beta$-SiC $\rightarrow \alpha$-SiC phase transformation. This allows, to conclude that changes in the mechanical properties occur as the result of the addition of the $\mathrm{Ti}_{3} \mathrm{C}_{2}$ phase.

A similar phenomenon of MXene phase decomposition with the formation of carbon structures was described by Naquib et al. [51]. As a result of flash oxidation of $2 \mathrm{D} \mathrm{Ti}_{3} \mathrm{C}_{2}$ at $1150{ }^{\circ} \mathrm{C}$ for $30 \mathrm{~s}$, a disordered graphitic carbon decorated with nanocrystalline anatase was obtained. Moreover, similar structures were produced by hydrothermal treatment of MXene at $150-250{ }^{\circ} \mathrm{C}$ or by oxidizing in $\mathrm{CO}_{2}$ at $150-300$ ${ }^{\circ} \mathrm{C}$. An attempt to explain the mechanisms responsible for the above phenomenon was made by Lotfi et.al. [52]. They investigated the oxidation of the MXene structure in different environments and compared the obtained results with the results of molecular dynamics simulations. The authors performed a series of MD-NVT simulations on MXenes in the presence of different molecules (200 oxygen molecules, 100 oxygen and 100 water molecules, 200 hydrogen peroxide molecules) and different temperatures $(1000 \mathrm{~K}, 1500 \mathrm{~K}$, $2000 \mathrm{~K}, 2500 \mathrm{~K}$ and $3000 \mathrm{~K}$ ). The Computational method was supported with the bond-order-based reactive force field technique (ReaxFF). The simulation, confirmed by the test results, showed that in the case of dry or wet air at the temperature of $1500 \mathrm{~K}$, the MXene phase oxidized and created graphite structures decorated with titanium oxides. This is demonstrated by the sudden increase in the number of $\mathrm{C}-\mathrm{C}$ and $\mathrm{Ti}-\mathrm{O}$ bonds with the simultaneous fall of Ti-C bonds. Heating the MXene in a vacuum resulted in the recrystallization of $\mathrm{Ti}_{3} \mathrm{C}_{2}$ into a cubic $\mathrm{TiC}$ and no carbon structures were formed (carbon residues evaporated as $\mathrm{CO}_{2}$ ). The transformation of MXene phases requires the titanium atoms to diffuse from the inside of the flakes. These atoms may diffuse both along the flakes and across, in the direction of the surface. As was mentioned in the work [52], the diffusion of titanium atoms to the flake surface causes major defects to the structure, which may disturb the creation of $\mathrm{C}-\mathrm{C}$ bonds. The carbon structures in the obtained composites demonstrate a major defect that may be observed in the HRTEM pictures and the arc shape of spots in FFT (Figs. 5c, $6 b)$. In the previous studies [53] concerning the influence of graphene on the mechanical properties of silicon carbide, graphene did not demonstrate such defects, which suggests that this phenomenon is not connected to the process of sintering itself. Presumably, it emerges from the genesis of these structures. This confirms the thesis about graphite structures being the effect of transformation of the added MXene phases.

To comprehend which creation mechanism of the hybrid structures may take place during the process of sintering composites in the $\mathrm{SiC} / \mathrm{C} / \mathrm{Ti}_{3} \mathrm{C}_{2}$ system, one must thoroughly trace the process conditions. The vacuum inside the SPS chamber is intended to protect the graphite parts (die, punches, and pistons), whereas the conditions between the particles of powder trapped in the graphite dye are different. Silicon carbide tends to passivate, which results in covering its particles with thin layers of $\mathrm{SiO}_{2}$. During the process of sintering, silica evaporates into the area between grains. In higher temperatures, these gases are enriched with gaseous $\mathrm{SiC}$, created as a result of thermal decomposition. Carbon, present during the sintering process, causes the reduction of silicon carbide as presented in the formula [54]:

$\mathrm{SiO}_{2}+\mathrm{nSiC}+3 \mathrm{C} \rightarrow(\mathrm{n}+1) \mathrm{SiC}+2 \mathrm{CO}$

More to the point, as studies show [55], one of the first stages of oxidizing the MXene phases which may occur in $200-400{ }^{\circ} \mathrm{C}$ is the loosing of $-\mathrm{OH},=\mathrm{O}$ and $-\mathrm{F}$ functional groups and physically adsorbed $\mathrm{H}_{2} \mathrm{O}$ from the surface. As a result of these factors, a mixture of $\mathrm{O}_{2}, \mathrm{CO}$ and $\mathrm{H}_{2} \mathrm{O}$ is obtained in the surrounding of $\mathrm{Ti}_{3} \mathrm{C}_{2}$ flakes. Some of these components, according to [52, 55], may be responsible for the creation of disordered carbon decorated with nanocrystalline anatase. In temperatures below $900{ }^{\circ} \mathrm{C}$, anatase particles may transform into a high-temperature variation called rutile. This melts at $1830{ }^{\circ} \mathrm{C}$ under standard pressure, thus at the sintering temperature above $1900{ }^{\circ} \mathrm{C}$ it may be subjected to melting and dissolving on the grains' boundaries in the close surroundings of disordered graphite. That, in turn, may impede its identification. Furthermore, a part of the rutile particles may be dispersed in carbon structures, which also makes its identification more difficult. However, this may clarify the accumulation of titanium within graphite flakes.

The above-mentioned oxidation of MXene phases results in the presence of disordered graphite flakes on the matrix grains' boundaries during the sintering process. Thus, like graphene, their occurrence tends to limit the growth of matrix grain, which is confirmed in Table 1 . This phenomenon will be reflected in the increase of hardness of the analyzed composites. A strong connection between the created structures and the matrix will result in the emergence of mechanisms such as delamination, bridging, and deflection of cracks, caused by the structures' geometry. The mechanisms mentioned are responsible for the increase of fracture toughness. The conditions essential for these to arise are the accurate geometry of the phase used and a proper interface. All kinds of discontinuities, such as porosity, voids, or an imperfect interface have a considerable influence on fracture 
toughness, which decreases with the increase of reinforcement phase (Table 1). The presence of such discontinuities is presumably connected to the flakes' tendency to agglomerate in the cases where the weight content of MXene structures is higher. This phenomenon is presented in Fig. 2.

\section{Conclusion}

Based on the obtained results, one can conclude that the addition of the $2 \mathrm{D} \mathrm{Ti}_{3} \mathrm{C}_{2}$ phase significantly increases the mechanical properties of silicon carbide. A thorough analysis of the composites produced allowed for the determination of the mechanism responsible for this phenomenon. During sintering, thermal decomposition of the MXene phases occurs, which results in the formation of disordered graphitic carbon. This is possible due to the combination of several factors, such as: novel sintering technology, the applied sintering aids, and accurate sintering conditions. The factors mentioned lead to the formation of the gas mixture rich in $\mathrm{O}_{2}$ and $\mathrm{H}_{2} \mathrm{O}$ in the space between the powder grains and flakes, which allows for the creation of defected graphite. The presence of these structures in the microstructure, in a similar way to the case of composites based on a ceramic matrix reinforced with graphene materials, leads to a reduction in grain growth, which results in an increase in hardness. In addition, due to their geometry, they are an effective barrier to the propagation of cracks, which translates into a nearly $50 \%$ increase in fracture toughness for only $0.2 \mathrm{wt} \%$ additions of the $2 \mathrm{D} \mathrm{Ti}_{3} \mathrm{C}_{2}$.

Funding Studies were funded by the Materials Technologies project granted by Warsaw University of Technology under the Excellence Initiative: Research University (ID-UB) programs.

\section{Declarations}

Conflicts of interest All Authors declare that they have no conflict of interest.

Ethical approval This article does not contain any studies with human participants or animals performed by any of the authors.

Open Access This article is licensed under a Creative Commons Attribution 4.0 International License, which permits use, sharing, adaptation, distribution and reproduction in any medium or format, as long as you give appropriate credit to the original author(s) and the source, provide a link to the Creative Commons licence, and indicate if changes were made. The images or other third party material in this article are included in the article's Creative Commons licence, unless indicated otherwise in a credit line to the material. If material is not included in the article's Creative Commons licence and your intended use is not permitted by statutory regulation or exceeds the permitted use, you will need to obtain permission directly from the copyright holder. To view a copy of this licence, visit http://creativecommons.org/licenses/by/4.0/.

\section{References}

1. Gubernat A, Stobierski L, Łabaj P. Microstructure and mechanical properties of silicon carbide pressureless sintered with oxide additives. J Eur Ceram Soc. 2007;27:781-9.

2. Rączka M, Górny G, Stobierski L, Rożniatowski K. Effect of carbon content on the microstructure and properties of silicon carbide-based sinters. Mater Charact. 2001;46:245-9.

3. Petrus M, Wozniak J, Cygan T, Adamczyk-Cieslak B, Kostecki M, Olszyna A. Sintering behaviour of silicon carbide matrix composites reinforced with multilayer graphene. Ceram Int. 2017;43:5007-13.

4. Guillard F, Allemand A, Lulewicz JD, Galy J. Densification of SiC by SPS-effects of time, temperature and pressure. J Eur Ceram Soc. 2007;27:2725-8.

5. Omori M. Sintering, consolidation, reaction and crystal growth by the spark plasma system (SPS). Mater Sci Eng A. 2000;287:183-8.

6. Munir ZA, Anselmi-Tamburini U, Ohyanagi M. The effect of electric field and pressure on the synthesis and consolidation of materials: a review of the spark plasma sintering method. J Mater Sci. 2006;41:763-77.

7. Vera MC, Ramirez-Rico J, Martinez-Fernandez J, Singh M. Sliding wear resistance of sintered $\mathrm{SiC}$-fiber bonded ceramics. Int J Refract Met Hard Mater. 2015;49:232-9.

8. Patent US. Silicon carbide reinforced silicon carbide composite. 2001.

9. Geim AK, Novoselov KS. The rise of graphene. Nat Mater. 2007;6:183-91.

10. Porwal H, Tatarko P, Saggar R, Grasso S, Kumar Mani M, Dlouhý I, et al. Tribological properties of silica-graphene nanoplatelet composites. Ceram Int. 2014;40:12067-74.

11. Hvizdoš P, Dusza J, Balázsi C. Tribological properties of Si3N4graphene nanocomposites. J Eur Ceram Soc. 2013;33:2359-64.

12. Porwal H, Tatarko P, Grasso S, Khaliq J, Dlouhý I, Reece MJ. Graphene reinforced alumina nano-composites. Carbon. 2013;64:359-69.

13. Porwal H, Grasso S, Reece MJ. Review of graphene-ceramic matrix composites. Adv Appl Ceram. 2013;112:443-54.

14. Nowotny VH. Strukturchemie einiger Verbindungen der Übergangsmetalle mit den elementen C, Si, Ge, Sn. Prog Solid State Chem. 1971;5:27-70.

15. Nowotny H, Boller H, Beckmann O. Alloy phases crystallizing with structures which occur with non-metallic compounds. J Solid State Chem. 1970;2:462-71.

16. Barsoum MW, El-Raghy T. The MAX phases: unique new carbide and nitride materials: tertiary ceramics are soft and machinable, yet heat-tolerant, strong and lighweight. Am Sci. 2001;89:334-43.

17. Barsoum MW. MN+1AXN phases: a new class of solids; thermodynamically stable nanolaminates. Prog Solid State Chem. 2000;28:201-81.

18. Naguib M, Unocic RR, Armstrong BL, Nanda J. Large-scale delamination of multi-layers transition metal carbides and carbonitrides 'mXenes.' Dalt Trans. 2015;44:9353-8.

19. Naguib M, Kurtoglu M, Presser V, Lu J, Niu J, Heon M, et al. Two-dimensional nanocrystals produced by exfoliation of Ti3AlC2. Adv Mater. 2011;23:4248-53. 
20. Rozmysłowska-Wojciechowska A, Szuplewska A, Wojciechowski T, Poźniak S, Mitrzak J, Chudy M, et al. A simple, low-cost and green method for controlling the cytotoxicity of MXenes. Mater Sci Eng C. 2020;111:110790.

21. Szuplewska A, Rozmysłowska-Wojciechowska A, Poźniak S, Wojciechowski T, Birowska M, Popielski M, et al. Multilayered stable 2D nano-sheets of Ti2NTx MXene: synthesis, characterization, and anticancer activity. J Nanobiotechnology. 2019;17:114.

22. Rasool K, Helal M, Ali A, Ren CE, Gogotsi Y, Mahmoud KA. Antibacterial activity of Ti3C2Tx MXene. ACS Nano. 2016;10:3674-84.

23. Liu Z, Zhao M, Lin H, Dai C, Ren C, Zhang S, et al. 2D magnetic titanium carbide MXene for cancer theranostics. J Mater Chem B. 2018;6:3541-8.

24. Naguib M, Come J, Dyatkin B, Presser V, Taberna PL, Simon $\mathrm{P}$, et al. MXene: a promising transition metal carbide anode for lithium-ion batteries. Electrochem commun. 2012;16:61-4.

25. Wang X, Kajiyama S, Iinuma H, Hosono E, Oro S, Moriguchi I, et al. Pseudocapacitance of MXene nanosheets for high-power sodium-ion hybrid capacitors. Nat Commun. 2015;6:1-6.

26. Xiong D, Li X, Bai Z, Lu S. Recent advances in layered $\mathrm{Ti}_{3}$ $\mathrm{C}_{2} \mathrm{~T}_{x}$ MXene for electrochemical energy storage. Small. 2018;14:1703419.

27. Peng YY, Akuzum B, Kurra N, Zhao MQ, Alhabeb M, Anasori $\mathrm{B}$, et al. All-MXene (2D titanium carbide) solid-state microsupercapacitors for on-chip energy storage. Energy Environ Sci. 2016;9:2847-54.

28. Anasori B, Lukatskaya MR, Gogotsi Y. 2D metal carbides and nitrides (MXenes) for energy storage. Nat Rev Mater. 2017;2:1-17.

29. Kalambate PK, Gadhari NS, Li X, Rao Z, Navale ST, Shen Y, et al. Recent advances in MXene-based electrochemical sensors and biosensors. Trends Anal Chem. 2019;120:115643.

30. Kim SJ, Koh HJ, Ren CE, Kwon O, Maleski K, Cho SY, et al. Metallic Ti3C2Tx mxene gas sensors with ultrahigh signal-tonoise ratio. ACS Nano. 2018;12:986-93.

31. Carey M, Hinton Z, Sokol M, Alvarez NJ, Barsoum MW. Nylon-6/ $\mathrm{Ti} 3 \mathrm{C} 2 \mathrm{Tz}$ MXene nanocomposites synthesized by in situ ring opening polymerization of $\epsilon$-caprolactam and their water transport properties. ACS Appl Mater Interfaces. 2019;11:20425-36.

32. Sheng X, Zhao Y, Zhang L, Lu X. Properties of two-dimensional Ti3C2 MXene/thermoplastic polyurethane nanocomposites with effective reinforcement via melt blending. Compos Sci Technol. 2019;181:107710.

33. Zhi W, Xiang S, Bian R, Lin R, Wu K, Wang T, et al. Study of MXene-filled polyurethane nanocomposites prepared via an emulsion method. Compos Sci Technol. 2018;168:404-11.

34. Ling Z, Ren CE, Zhao MQ, Yang J, Giammarco JM, Qiu J, et al. Flexible and conductive MXene films and nanocomposites with high capacitance. Proc Natl Acad Sci USA. 2014;111:16676-81.

35. Liu R, Li W. High-thermal-stability and High-thermal-conductivity Ti3C2T x MXene/poly(vinyl alcohol) (PVA) composites. ACS Omega. 2018;3:2609-17.

36. Cao Y, Deng Q, Liu Z, Shen D, Wang T, Huang Q, et al. Enhanced thermal properties of poly(vinylidene fluoride) composites with ultrathin nanosheets of MXene. RSC Adv. 2017;7:20494-501.

37. Hu J, Li S, Zhang J, Chang Q, Yu W, Zhou Y. Mechanical properties and frictional resistance of $\mathrm{Al}$ composites reinforced with Ti3C2Tx MXene. Chin Chem Lett. 2020;31:996-9.

38. Guo L, Zhang Y, Zhang G, Wang Q, Wang T. MXene-A12O3 synergize to reduce friction and wear on epoxy-steel contacts lubricated with ultra-low sulfur diesel. Tribol Int. 2021. https:// doi.org/10.1016/j.triboint.2020.106588.

39. Ronchi RM, Arantes JT, Santos SF. Synthesis, structure, properties and applications of MXenes: current status and perspectives. Ceram Int. 2019;45:18167-88.
40. Fei M, Lin R, Lu Y, Zhang X, Bian R, Cheng J, et al. MXene-reinforced alumina ceramic composites. Ceram Int. 2017;43:17206-10.

41. Cygan T, Wozniak J, Petrus M, Lachowski A, Pawlak W, Adamczyk-Cieślak B, et al. Microstructure and mechanical properties of alumina composites with addition of structurally modified 2D Ti3C2 (MXene) phase. Materials. 2021;14:829.

42. Guo J, Legum B, Anasori B, Wang K, Lelyukh P, Gogotsi Y, et al. Cold sintered ceramic nanocomposites of 2D MXene and zinc oxide. Adv Mater. 2018;30:1801846.

43. Wozniak J, Petrus M, Cygan T, Jastrzębska A, Wojciechowski $\mathrm{T}$, Ziemkowska W, et al. Silicon carbide matrix composites reinforced with two-dimensional titanium carbide-Manufacturing and properties. Ceram Int. 2019;45:6624-31.

44. Wozniak J, Petrus M, Cygan T, Lachowski A, Adamczyk-Cieślak $\mathrm{B}$, Moszczyńska D, et al. Influence of mxene (Ti3C2) phase addition on the microstructure and mechanical properties of silicon nitride ceramics. Materials. 2020;13:1-11.

45. Ding J, Chen F, Chen J, Liang J, Kong J. MXene-derived TiC/ SiBCN ceramics with excellent electromagnetic absorption and high-temperature resistance. J Am Ceram Soc. 2021;104:1772-84.

46. Jastrzębska AM, Szuplewska A, Wojciechowski T, Chudy M, Ziemkowska W, Chlubny L, et al. In vitro studies on cytotoxicity of delaminated Ti3C2 MXene. J Hazard Mater. 2017;339:1-8.

47. Petrus M, Wozniak J, Jastrzębska A, Kostecki M, Cygan T, Olszyna A. The effect of the morphology of carbon used as a sintering aid on the sinterability of silicon carbide. Ceram Int. 2018:44:7020-5.

48. Wojciechowski T, Rozmysłowska-Wojciechowska A, Matyszczak G, Wrzecionek M, Olszyna A, Peter A, et al. Ti2C MXene modified with ceramic oxide and noble metal nanoparticles: synthesis, morphostructural properties, and high photocatalytic activity. Inorg Chem. 2019;58:7602-14.

49. Cygan T, Wozniak J, Kostecki M, Petrus M, Jastrzębska A, Ziemkowska W, et al. Mechanical properties of graphene oxide reinforced alumina matrix composites. Ceram Int. 2017;43:6180-6.

50. Feng W, Luo H, Wang Y, Zeng S, Deng L, Zhou X, et al. Ti3C2 MXene: a promising microwave absorbing material. RSC Adv. 2018;8:2398-403.

51. Naguib M, Mashtalir O, Lukatskaya MR, Dyatkin B, Zhang C, Presser V, et al. One-step synthesis of nanocrystalline transition metal oxides on thin sheets of disordered graphitic carbon by oxidation of MXenes. Chem Commun. 2014;50:7420-3.

52. Lotfi R, Naguib M, Yilmaz DE, Nanda J, Van Duin ACT. A comparative study on the oxidation of two-dimensional Ti3C2 MXene structures in different environments. J Mater Chem A. 2018;6:12733-43.

53. Petrus M, Wozniak J, Cygan T, Kostecki M, Olszyna A. The effect of the morphology of carbon used as a sintering aid on the mechanical properties of silicon carbide. Ceram Int. 2019;45:1820-4.

54. Stobierski L, Gubernat A. Sintering of silicon carbideI. Eff Carbon Ceram Int. 2003;29:287-92.

55. Li Z, Wang L, Sun D, Zhang Y, Liu B, Hu Q, et al. Synthesis and thermal stability of two-dimensional carbide MXene Ti3C2. Mater Sci Eng B Solid State Mater Adv Tech. 2015;191:33-40.

Publisher's Note Springer Nature remains neutral with regard to jurisdictional claims in published maps and institutional affiliations. 